\title{
Voice Outcomes After Transoral Laser Microsurgery or Radiotherapy in Early Glottic Cancer: Factors to Consider
}

\author{
Jung Je Park (i) · Seongjun Won (i) \\ Department of Otorhinolaryngology-Head and Neck Surgery, Gyeongsang National University Hospital, Institute of Health Sciences, \\ School of Medicine, Gyeongsang National University, Jinju, Korea
}

Treatment goals in patients with early glottic cancer include maximizing local control of the disease and preserving the function of the larynx as much as possible. Standard treatments for early glottic cancer include transoral laser microsurgery (TLM) and radiotherapy (RT), which were reported to result in similar oncologic outcomes [1]. More recent studies comparing the two treatment methods, however, have yielded inconsistent findings. For example, one study found that survival was longer in patients with Tis/T1a glottic cancer who underwent TLM than RT [2], whereas another study found that oncologic recurrence rates were higher in patients with $\mathrm{T} 1 \mathrm{a}$ and $\mathrm{T} 1 \mathrm{~b}$ glottic cancer treated with TLM than with RT [3]. In contrast to both, a third study found no difference in 5-year local control rate between TLM and RT in patients with T2 glottic cancer [4]. Nevertheless, the oncologic outcomes of both treatments are excellent in patients with early glottic cancer. Because both TLM and RT provide comparable oncological outcomes, quality of life (QOL) considerations, such as voice outcomes, cost, and duration of treatment, are important in determining the primary treatment modality in individual patients.

Patients with early glottic cancer experience voice changes after both TLM and RT. Many studies have been performed to clarify differences in voice changes between these treatment methods. Although several studies have reported that voice outcomes after TLM are superior to those after RT [5-7], other studies have reported that voice quality is better after RT than after TLM [8-10]. Studies have also found that self-rated voicerelated QOL is similar in patients with early glottic carcinoma treated with RT and TLM [11,12], although one of these studies found that objective parameters, including jitter, shimmer, fundamental frequency, and noise/harmonic ratio, are compromised
afterTLM [11].

One important reason for these conflicting results is the lack of a standard method for evaluating voice outcomes. Some studies used self-assessment tools, such as the Voice Handicap Index (VHI), and perceptual evaluation tools, such as the GRBAS (grade, roughness, breathiness, asthenia, and strain) rating scale. Other studies focused on instrumental assessments, such as laryngeal imaging, acoustic analysis, and aerodynamic assessment. Moreover, studies have reported voice outcomes at different followup periods.

Treatment characteristics can also affect voice outcomes. For example, voice outcomes in patients who undergo TLM can depend on the extent of surgical resection. Generally, better VHI outcomes were reported following lower-grade (European Laryngological Society Classification of cordectomies type [ELS] I\&II) than higher-grade (ELS III) resection [13], and voice outcomes in patients who undergo RT are affected by radiation dose. Voice outcomes are also affected by individual factors, including smoking status, chronic disease, and previous surgery.

It is not yet possible to determine whether TLM or RT provides superior voice outcomes. Therefore, in making treatment decisions for patients with early glottic cancer, clinicians should consider various factors, including the uncertainties, risks, and benefits of each method, and should fully discuss these factors with their patients.

\section{CONFLICT OF INTEREST}

No potential conflict of interest relevant to this article was reported.

Copyright (C) 2019 by Korean Society of Otorhinolaryngology-Head and Neck Surgery.

This is an open-access article distributed under the terms of the Creative Commons Attribution Non-Commercial License (http://creativecommons.org/licenses/by-nc/4.0)

which permits unrestricted non-commercial use, distribution, and reproduction in any medium, provided the original work is properly cited. 


\section{ORCID}

Jung Je Park https://orcid.org/0000-0001-6325-0398

SeongjunWon https://orcid.org/0000-0003-4163-4053

\section{REFERENCES}

1. Peretti G, Nicolai P, Piazza C, Redaelli de Zinis LO, Valentini S, Antonelli AR. Oncological results of endoscopic resections of Tis andT1 glottic carcinomas by carbon dioxide laser. Ann Otol Rhinol Laryngol. 2001 Sep;110(9):820-6.

2. Guimaraes AV, Dedivitis RA, Matos LL, Aires FT, Cernea CR. Comparison between transoral laser surgery and radiotherapy in the treatment of early glottic cancer: a systematic review and meta-analysis. Sci Rep. 2018 Aug;8(1):11900.

3. Gioacchini FM,Tulli M, Kaleci S, Bondi S, Bussi M, Re M.Therapeutic modalities and oncologic outcomes in the treatment of T1b glottic squamous cell carcinoma: a systematic review. Eur Arch Otorhinolaryngol. 2017 Dec;274(12):4091-102.

4. Warner L, Lee K, Homer JJ. Transoral laser microsurgery versus radiotherapy for T2 glottic squamous cell carcinoma: a systematic review of local control outcomes. Clin Otolaryngol. 2017 Jun;42(3): 629-36.

5. Du G, Liu C, Yu W, Li J, Li W, Wang C, et al. Voice outcomes after laser surgery vs. radiotherapy of early glottic carcinoma: a meta-analysis. Int J Clin Exp Med. 2015 Oct;8(10):17206-13.

6. Gandhi S, Gupta S, Rajopadhye G. A comparison of phonatory outcome between trans-oral $\mathrm{CO}(2)$ laser cordectomy and radiotherapy in T1 glottic cancer. Eur Arch Otorhinolaryngol. 2018 Nov;275(11):
2783-6.

7. Hong YT, Park MJ, Hong KH. Characteristics of speech production in patients with $\mathrm{T} 1$ glottic cancer who underwent laser cordectomy or radiotherapy. Logoped PhoniatrVocol. 2018 Oct;43(3):120-8.

8. Jotic A, Stankovic P, Jesic S, Milovanovic J, Stojanovic M, Djukic V. Voice quality after treatment of early glottic carcinoma. JVoice. 2012 May;26(3):381-9.

9. Kerr P, Mark Taylor S, Rigby M, Myers C, Osborn H, Lambert P, et al. Oncologic and voice outcomes after treatment of early glottic cancer: transoral laser microsurgery versus radiotherapy. J Otolaryngol Head Neck Surg. 2012 Dec;41(6):381-8.

10. Lee SH, Hong KH, Kim JS, Hong YT. Perceptual and acoustic outcomes of early-stage glottic cancer after laser surgery or radiotherapy: a meta-analysis. Clin Exp Otorhinolaryngol. 2019 Aug;12(3): 241-8.

11. Lombardo N,Aragona T,Alsayyad S, Pelaia G, Terracciano R, Savino R. Objective and self-evaluation voice analysis after transoral laser cordectomy and radiotherapy in T1a-T1b glottic cancer. Lasers Med Sci. 2018 Jan;33(1):141-7.

12. Osborn HA, Hu A, Venkatesan V, Nichols A, Franklin JH, Yoo JH, et al. Comparison of endoscopic laser resection versus radiation therapy for the treatment of early glottic carcinoma. J Otolaryngol Head Neck Surg. 2011 Jun;40(3):200-4.

13. Kinshuck AJ, Shenoy A, Jones TM. Voice outcomes for early laryngeal cancer. Curr Opin Otolaryngol Head Neck Surg. 2017 Jun;25(3): 211-6.

Received May 24, 2019 Accepted June 24, 2019 